\title{
Echolocation click source parameters of Australian snubfin dolphins (Orcaella heinsohni)
}

Mafalda de Freitas, Joshua N. Smith, Frants H. Jensen, Kristian Beedholm, and Peter T. Madsen

Citation: The Journal of the Acoustical Society of America 143, 2564 (2018); doi: 10.1121/1.5034174

View online: https://doi.org/10.1121/1.5034174

View Table of Contents: http://asa.scitation.org/toc/jas/143/4

Published by the Acoustical Society of America

\section{Articles you may be interested in}

Whistle description of Irrawaddy dolphins (Orcaella brevirostris) in Bay of Brunei, Sarawak, Malaysia

The Journal of the Acoustical Society of America 143, 2708 (2018); 10.1121/1.5036926

Unknown beaked whale echolocation signals recorded off eastern New Zealand

The Journal of the Acoustical Society of America 143, EL285 (2018); 10.1121/1.5032127

Song recorded near a super-group of humpback whales on a mid-latitude feeding ground off South Africa

The Journal of the Acoustical Society of America 143, EL298 (2018); 10.1121/1.5032126

Hearing thresholds, for underwater sounds, of harbor seals (Phoca vitulina) at the water surface

The Journal of the Acoustical Society of America 143, 2554 (2018); 10.1121/1.5034173

Finite element simulation of broadband biosonar signal propagation in the near- and far-field of an echolocating Atlantic bottlenose dolphin (Tursiops truncatus)

The Journal of the Acoustical Society of America 143, 2611 (2018); 10.1121/1.5034464

Sounds of Arctic cod (Boreogadus saida) in captivity: A preliminary description

The Journal of the Acoustical Society of America 143, EL317 (2018); 10.1121/1.5035162 


\title{
Echolocation click source parameters of Australian snubfin dolphins (Orcaella heinsohni) (L)
}

\author{
Mafalda de Freitas ${ }^{a)}$ \\ Department of Bioscience, Aarhus University, Building 1131, C.F. Moellers Alle 3, DK-8000 Aarhus C, \\ Denmark

\begin{abstract}
Joshua N. Smith
Murdoch University Cetacean Research Unit, School of Veterinary and Life Sciences, Murdoch University, South Street, Murdoch, Western Australia, 6150, Australia
\end{abstract}

Frants H. Jensen ${ }^{\text {b) }}$

Aarhus Institute of Advanced Studies, Aarhus University, Hфegh-Guldbergs Gade 6B, 8000 Aarhus C, Denmark

\author{
Kristian Beedholm and Peter T. Madsen ${ }^{\text {c) }}$ \\ Department of Bioscience, Aarhus University, Building 1131, C.F. Moellers Alle 3, DK-8000 Aarhus C, \\ Denmark
}

(Received 17 January 2018; revised 13 March 2018; accepted 5 April 2018; published online 30 April 2018)

\begin{abstract}
The Australian snubfin dolphin (Orcaella heinsohni) is endemic to Australian waters, yet little is known about its abundance and habitat use. To investigate the feasibility of Passive Acoustic Monitoring for snubfin dolphins, biosonar clicks were recorded in Cygnet Bay, Australia, using a four-element hydrophone array. Clicks had a mean source level of $200 \pm 5 \mathrm{~dB}$ re $1 \mu \mathrm{Pa}$ pp, transmission directivity index of $24 \mathrm{~dB}$, mean centroid frequency of $98 \pm 9 \mathrm{kHz}$, and a root-mean-square bandwidth of $31 \pm 3 \mathrm{kHz}$. Such properties lend themselves to passive acoustic monitoring, but are comparable to similarly-sized delphinids, thus requiring additional cues to discriminate between snubfins and sympatric species. (C) 2018 Acoustical Society of America.
\end{abstract}

https://doi.org/10.1121/1.5034174

[WWA]

Pages: 2564-2569

\section{INTRODUCTION}

The Australian snubfin dolphin (Orcaella heinsohni, hereafter snubfin) has recently been described as a new species, distinct from the Irrawaddy dolphin (Orcaella brevirostris) (Beasley et al., 2005) and considered endemic to Australian waters (Palmer et al., 2011). However, little is known about the geographical range and acoustic repertoire of this species, and it is thought that their fragmented costal populations (Allen et al., 2012; Parra et al., 2006a) are highly susceptible to human encroachment from hastening coastal development (Brown et al., 2012; Parra et al., 2006a). Consequently, recent global assessments by Reeves et al. (2008) placed snubfins in the International Union for Conservation of Nature (IUCN) category of "near threatened" (Brown et al., 2014) and they have since become a primary focus for conservation efforts in the region (Bejder et al., 2012).

Attempts to quantify populations and habitat ranges of snubfins have, so far, mostly been undertaken through visual surveys (Parra et al., 2006a, 2006b), opportunistic sightings (Allen et al., 2012; Palmer et al., 2014), and stranding data

\footnotetext{
${ }^{a)}$ Electronic mail: mafalda.df@gmail.com

${ }^{b)}$ Also at: Biology Department, Woods Hole Oceanographic Institution, Woods Hole, MA 02543, USA.

${ }^{c}$ Also at: Aarhus Institute of Advanced Studies, Aarhus University, HøeghGuldbergs Gade 6B, 8000 Aarhus C, Denmark.
}

(Chatto and Warneke, 2000). These methods, although practical, limit detections to daylight hours, favorable weather, and accessible locations. As a result, there is growing interest in employing passive acoustic monitoring (PAM) methods that are increasingly used worldwide to monitor marine mammal species (Kyhn et al., 2012; Marques et al., 2009). However, PAM critically relies on using equipment that covers the bandwidth of the emitted sounds and on detection and classification routines that exploit species-specific vocal repertoire features. Unfortunately, knowledge of the snubfin acoustic repertoire remains limited with only two studies to date having described whistles and other social sounds (Berg Soto et al., 2014; Van Parijs et al., 2000). In addition, whistles are primarily produced in social contexts (Janik and Sayigh, 2013), and may as such not reliably demonstrate presence of individuals in a given area. Echolocation, however, is a primary sensory modality that is used for orientation, navigation, and foraging in odontocetes ( $\mathrm{Au}, 1993)$, and makes up the largest portion of odontocete acoustic output. The different echolocation signal types produced by odontocete species (Fenton et al., 2014) have already proven to be successful in PAM (Au et al., 2013; Roch et al., 2011). Echolocation clicks are therefore useful for PAM if their species-specific properties are known.

Here we present click source parameter estimates for the Australian snubfin, a poorly known odontocete species endemic to coastal Australian waters, with relevance for future application in PAM efforts. 


\section{MATERIALS AND METHODS}

\section{A. Recording site}

Acoustic recordings were conducted in a shallow-water area during daylight hours within the Fitzroy River, Gladstone on the east Australian coast in May 2013 and Cygnet Bay in the Kimberly, north-west Australia (16 $34^{\prime}$ $\mathrm{S}, 123^{\circ} 00^{\prime} \mathrm{E}$ ) in September 2013. A $6 \mathrm{~m}$ research vessel was used in the Fitzroy River and a $5.6 \mathrm{~m}$ research vessel was used in Cygnet Bay, both with two observers on board conducting acoustic recordings and visual observations. When a group of dolphins was encountered, the group size, behavior, and photo-identification of individuals were recorded. When acoustic recordings with good signal-to-noise ratio of dolphin vocalizations were considered feasible, the research vessel was maneuvered into a position to maximize the encounter time of the acoustic recorder with the group of dolphins without repositioning the vessel, and the engine was turned off.

\section{B. Recording equipment}

We used a linear vertical array with four Reson TC4034 (Reson A/S, Slangerup, Denmark) hydrophones fixed $0.9 \mathrm{~m}$ apart, facing the same direction, and inserted into a hollow poly-vinyl chloride (PVC) tube (see Kyhn et al., 2010 for details). The array was suspended from a surface buoy with the top hydrophone at $1.5 \mathrm{~m}$ depth and bottom hydrophone at $4.2 \mathrm{~m}$ depth followed by a $5 \mathrm{~kg}$ lead weight to keep the array vertical. Hydrophones were connected to two custom-built four-channel amplifier boxes with filters $(1 \mathrm{kHz}$ one pole high-pass, $200 \mathrm{kHz}$, four pole low-pass filter, Butterworth, $40 \mathrm{~dB}$ gain) and digitized by four analog-to-digital converter channels of a National Instruments USB-6251 multifunction device (National Instruments, Austin, TX) sampling 16-bit data at $500 \mathrm{kHz}$ per channel. The resulting recording chain had a flat frequency response $( \pm 2 \mathrm{~dB})$ between $1 \mathrm{kHz}$ and $200 \mathrm{kHz}$ and clip level of $192 \mathrm{~dB}$ re $1 \mu \mathrm{Pa}$ (peak), dictated by the maximum voltage of $\pm 5 \mathrm{~V}$ of the $\mathrm{A} / \mathrm{D}$ converter. All recordings were manually started and terminated, with data files streamed directly to the recording laptop hard disk. The recording array and localization routine was calibrated in a previous study (Kyhn et al., 2010).

\section{Click analysis}

Click analysis was carried out following procedures from de Freitas et al. (2015) and Madsen and Wahlberg (2007). A custom-written click extraction and analysis toolbox for delphinid echolocation (Biosonar array toolbox, F. H. Jensen) in MATLAB 7.0 (Mathworks, Inc., Natwick, MA) was used for analysing recordings. Odontocete biosonar is highly directional and thus prone to distortion resulting in much lower apparent source levels when recorded off the acoustic axis. Consequently, an established set of criteria (Kyhn et al., 2009; Madsen and Wahlberg, 2007) was used to maximize the number of "on-axis" clicks analyzed. Clicks were selected if they (1) were detected on all four hydrophones; (2) could be localized; (3) had the highest received level in a scan of clicks, determined by a series of at least five clicks with increasing and subsequently decreasing amplitude; (4) the highest received level was recorded on one of the two middle hydrophones. Clicks from buzzes, determined as multiple low source level clicks with repetitions rates below $3 \mathrm{~ms}$ were not included. All extracted clicks were visually verified to ensure they did not contain visible surface or bottom reflections.

Source parameters from each on-axis click were quantified sensu Madsen and Wahlberg (2007) and Au (1993). All clicks were high-pass filtered at $10 \mathrm{kHz}$ to reduce the influence of low frequency noise on parameter values. Click waveforms were interpolated by a factor of 10 by expanding the length of the complex Fourier spectrum before inverse transforming it back into the time domain. The duration $\left(D_{-10 \mathrm{~dB}}\right)$ of the click was determined as the time interval between the $-10 \mathrm{~dB}$ end points relative to the peak of the waveform envelope as calculated using the absolute value of the analytical signal. Received levels of each on-axis click were calculated as peak-to-peak (pp) and root-mean-square (rms) sound pressure within the $D_{-10} \mathrm{~dB}$ window, and energy-flux-density (EFD) was calculated as the sum of the squared sound pressure values within the $D_{-10}$ dB window. Inter-click intervals (ICI) were determined as the time between the peak envelope of the on-axis click and that of the previous click (Au, 1993). Click power spectra were calculated as the squared absolute values of the Fourier transform of clicks weighted by a 320-point Hann window centered on the time centroid of the envelope. Spectral parameters in the form of peak frequency $(\mathrm{Fp})$; centroid frequency $(\mathrm{Fc}) ;-3 \mathrm{~dB}$ and $-10 \mathrm{~dB}$ bandwidths; rms bandwidth, defined as the spectral standard deviation around the centroid frequency; $Q$ factor, defined as the ratio of the centroid frequency to the rms bandwidth (Au, 1993, 2004), were computed from the respective power spectra.

Source levels were computed for each on-axis click by adding the transmission loss between the source and the receiver to the recorded received level values. Transmission loss was calculated from the sum of spherical spreading (20 $\log R$ ) and the frequency-dependent absorption $(\alpha)$ over a given range $(R)$. An absorption coefficient of $0.025 \mathrm{~dB} \mathrm{~m}^{-1}$ was estimated from a water temperature of $24^{\circ} \mathrm{C}$ and a centroid frequency of $90 \mathrm{kHz}$.

\section{Beam estimates}

A composite measure of the sonar beam transmission directivity in the vertical plane was estimated following the procedure in Jensen et al. (2015). For beam pattern estimation, clicks localized outside $15 \mathrm{~m}$ were ignored. Since the acoustic axis of clicks scanning across the array could lie between hydrophones, we estimated the angle of incidence and relative rms intensity at each hydrophone relative to the peak of a quadratic interpolation of received intensity across three hydrophones. Relative intensity and angle of incidence for each hydrophone were pooled across clicks and used to fit the transmission pattern of a flat, circular piston of varying diameter (see Beedholm and Møhl, 2006; Kyhn et al., 2009). The full bandwidth directivity index and beam width were then calculated for the best-fitting circular piston using 

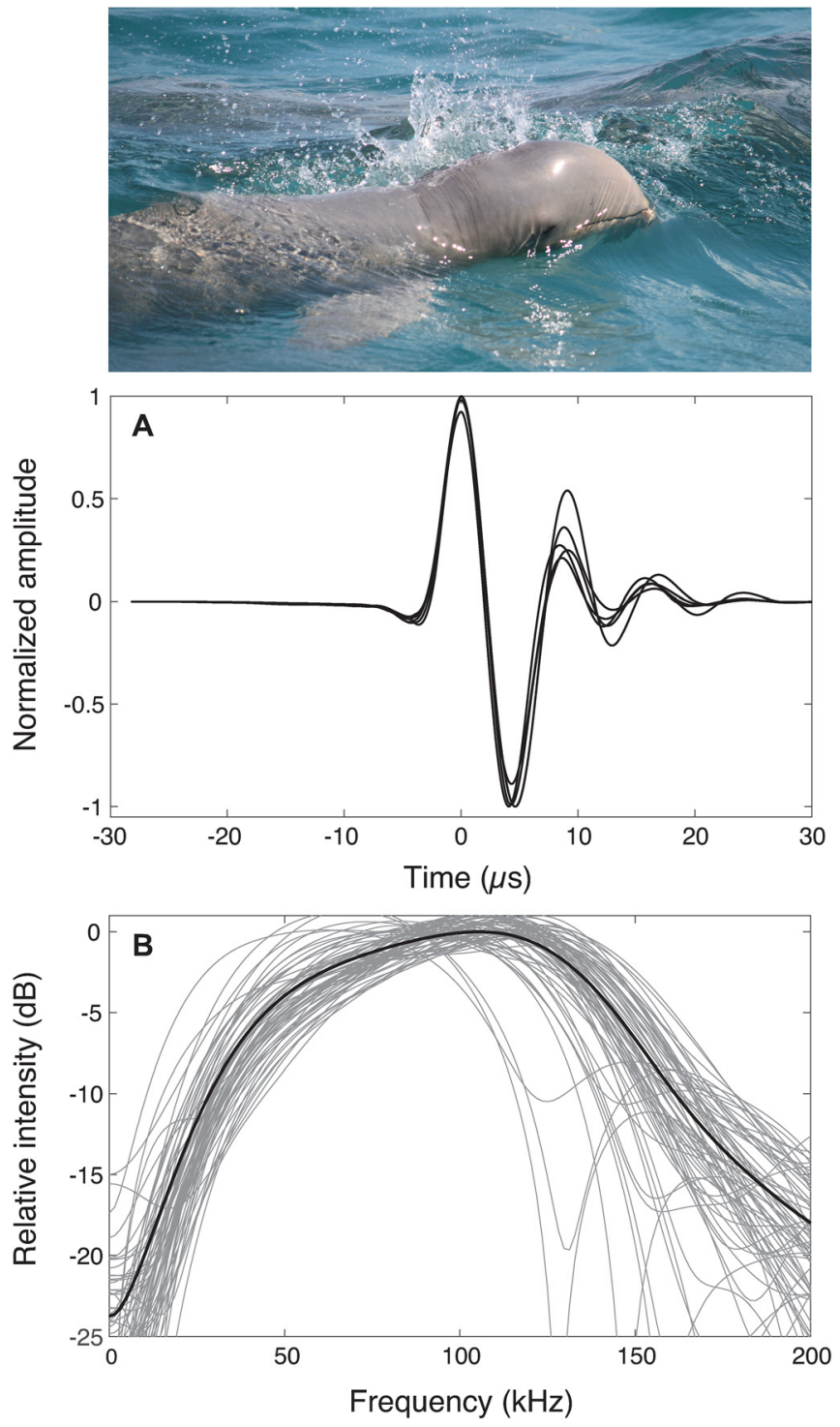

FIG. 1. (Color online) Time domain representations and power spectra of recorded on-axis echolocation clicks from Australian snubfin dolphin (Orcaella heinsohni). (A) Signal waveforms of the five clicks with the highest source levels are plotted, interpolated by a factor of 10. (B) Individual power spectra of all extracted on-axis clicks (grey lines) with the average power spectrum (black line) overlaid. (Sampling frequency $500 \mathrm{kHz}$, $N=320$-point discrete Fourier transform, Hann window, spectra normalized around the mean of the spectrum.) Photo credit: Josh N Smith. a model on-axis click. Confidence intervals were estimated using a bootstrap method sampling clicks with replacement for each of 2000 total bootstraps (Jensen et al., 2015).

\section{RESULTS}

Over two hours of snubfin recordings were made during the 19-day study period, and a total of 64 on-axis clicks were isolated from 8439 recorded echolocation clicks. Snubfins produced short duration [mean \pm standard deviation (SD); $12 \pm 1 \mu \mathrm{s}$ ] broadband transients (Fig. 1; Table I) with a mean peak-peak source level of $200 \pm 5 \mathrm{~dB}$ re $1 \mu \mathrm{Pa}$ and an EFD source level of $141 \pm 5 \mathrm{~dB}$ re $1 \mu \mathrm{Pa}^{2}$ s. Power spectra of onaxis clicks appeared unimodal, although occasional bimodal spectra were also present, with emphasis around $110 \mathrm{kHz}$. The steep decline in the power spectra around $180 \mathrm{kHz}$ is due to the steep low pass filter of the recording system. Clicks had a centroid frequency of $98 \pm 9 \mathrm{kHz}$ and a rms bandwidth of $31 \pm 3 \mathrm{kHz}$ (Fig. 2) and click trains were characterized by short ICIs $(52.2 \pm 27.7 \mathrm{~ms})$. Using ten snubfin clicks recorded within $15 \mathrm{~m}$, an equivalent piston radius (EPR) of $4.34 \mathrm{~cm}$ was estimated with confidence intervals of $3.95-4.72 \mathrm{~cm}$. The composite transmission beam pattern of snubfins has a $-3 \mathrm{~dB}$ beam width of 12.37 degrees and a $-10 \mathrm{~dB}$ beam width of 31.14 degrees with a directivity index of $23.5 \mathrm{~dB}$. Numerous snubfins were found in the area and different groups approached the array at any one time, making it unlikely that repeated individuals were recorded.

\section{DISCUSSION}

The newly described Australian snubfin dolphin is relatively poorly studied with little known about its habitat range, population structure, and relative abundance (Allen et al., 2012; Bejder et al., 2012). Consequently, there has been an increased interest in its acoustic repertoire for use in PAM for conservation efforts. As echolocation is a key sensory modality for all odontocetes, and since small odontocetes seem to echolocate near-continuously in the wild (Wisniewska et al., 2016), this study sought to parameterize the biosonar source parameters of this newly described species for use in PAM efforts.

Snubfins produced short duration, broadband transient clicks (Fig. 1), with high peak, centroid frequency, and broad bandwidths that are characteristic of this signal type (Au,
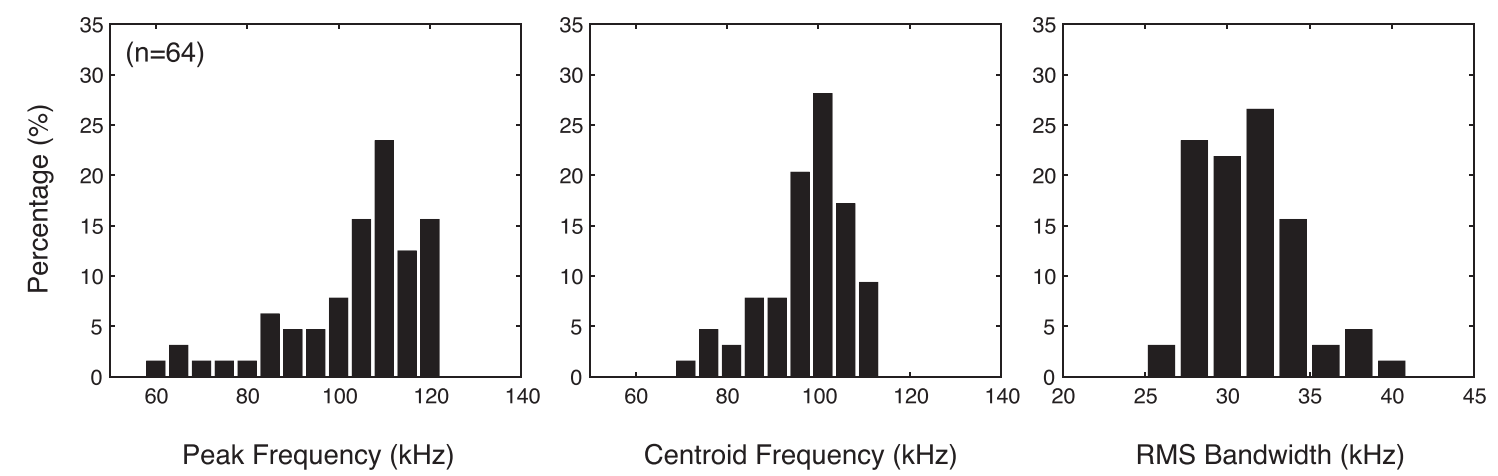

FIG. 2. Histogram of peak frequency, centroid frequency, and rms bandwidth for on-axis clicks of Australian snubfin. Binwidths for both peak and centroid frequencies are $5 \mathrm{kHz}$, while binwidth for rms bandwidth is $2 \mathrm{kHz}$. 
TABLE I. Mean ( \pm SD) echolocation source parameters of Australian snubfin Orcaella heinsohni and other sympatric delphinids.

\begin{tabular}{|c|c|c|c|c|c|c|c|c|}
\hline \multirow[b]{4}{*}{ Parameters } & \multicolumn{4}{|c|}{ Jensen et al. (2013) } & \multicolumn{4}{|c|}{ de Freitas et al. (2015) } \\
\hline & \multicolumn{2}{|c|}{ Snubfin } & \multicolumn{2}{|c|}{ Irrawaddy River dolphin } & \multicolumn{2}{|c|}{ Humpback } & \multicolumn{2}{|c|}{ Indo-Pacific Bottlenose dolphin } \\
\hline & \multicolumn{2}{|c|}{ Orcaella heinsohni } & \multicolumn{2}{|c|}{ Orcaella brevirostris } & \multicolumn{2}{|c|}{ Sousa sahulensis } & \multicolumn{2}{|c|}{ Tursiops aduncus } \\
\hline & Mean $( \pm S D)$ & Range & Mean $( \pm S D)$ & Range & Mean $( \pm S D)$ & Range & Mean $( \pm \mathrm{SD})$ & Range \\
\hline $\mathrm{ASL}_{\mathrm{pp}}(\mathrm{dB}$ re $1 \mu \mathrm{Pa} \mathrm{pp})$ & $200( \pm 5)$ & $184-210$ & $195( \pm 4)$ & $189-200$ & $199( \pm 3)$ & 194-208 & $204( \pm 4)$ & $193-214$ \\
\hline $\mathrm{ASL}_{\text {R.M.S. }}(\mathrm{dB}$ re $1 \mu \mathrm{Pa} \mathrm{rms})$ & $190( \pm 5)$ & $175-200$ & $185( \pm 4)$ & $180-191$ & $189( \pm 3)$ & $183-198$ & $195( \pm 4)$ & $183-204$ \\
\hline $\operatorname{ASL}_{\mathrm{EFD}}\left(\mathrm{dB}\right.$ re $\left.1 \mu \mathrm{Pa}^{2} \mathrm{~s}\right)$ & $141( \pm 5)$ & $126-151$ & $136( \pm 3)$ & $131-142$ & $141( \pm 3)$ & $136-149$ & $146( \pm 5)$ & $134-156$ \\
\hline$D_{-10 \mathrm{~dB}}$ Duration $(\mu \mathrm{s})$ & $12( \pm 1)$ & $11-17$ & $13( \pm 3)$ & $10-21$ & $15( \pm 2)$ & $10-20$ & $14( \pm 2)$ & $10-19$ \\
\hline Centroid frequency $(\mathrm{kHz})$ & $98( \pm 9)$ & $71-114$ & $95( \pm 10)$ & $70-109$ & $106( \pm 11)$ & $86-125$ & $112( \pm 9)$ & $82-129$ \\
\hline Peak frequency $(\mathrm{kHz})$ & $104( \pm 15)$ & $61-123$ & $101( \pm 20)$ & $65-125$ & $114( \pm 12)$ & $86-135$ & $124( \pm 13)$ & $53-141$ \\
\hline$-3 \mathrm{~dB}$ Bandwidth $(\mathrm{kHz})$ & $69( \pm 11)$ & $52-102$ & $64( \pm 16)$ & 40-91 & $59( \pm 18)$ & $42-114$ & $62( \pm 17)$ & $40-108$ \\
\hline$-10 \mathrm{~dB}$ Bandwidth $(\mathrm{kHz})$ & $124( \pm 12)$ & $92-164$ & $118( \pm 15)$ & $84-144$ & $116( \pm 20)$ & $86-163$ & $140( \pm 17)$ & $92-178$ \\
\hline rms Bandwidth (kHz) & $31( \pm 3)$ & $26-40$ & $30( \pm 4)$ & $22-37$ & $29( \pm 4)$ & $24-39$ & $34( \pm 3)$ & $29-40$ \\
\hline QR.M.S. & $3.2( \pm 0.4)$ & $1.9-3.8$ & $3.2( \pm 0.3)$ & $3-4$ & $3.7( \pm 0.7)$ & $2.6-4.7$ & $3.3( \pm 0.4)$ & $2.3-4.3$ \\
\hline Range (m) & $34( \pm 16)$ & $4-59$ & & & $32( \pm 10)$ & $24-60$ & $26( \pm 10)$ & $9-55$ \\
\hline$N$ & 64 & & 15 & & 42 & & 54 & \\
\hline
\end{tabular}

2004; Wahlberg et al., 2011) and comparable to similarly sized delphinids (Table I; Jensen et al., 2013). The source levels and transmission directivity index derived for snubfins were also within a comparable range to other small delphinids in similar habitats (Table I; Jensen et al., 2013). This suggests that delphinids of a similar size, within similar habitats, exhibit biosonar parameters within a consistent range that could be shaped by similar evolutionary drivers (Fenton et al., 2014). Nevertheless, while these biosonar parameters occur within similar ranges, a degree of plasticity is achieved by actively controlling source level (Moore and Patterson, 1983), frequency content (Moore and Pawloski, 1990) and beamwidth (Moore et al., 2008) of their biosonar, even in the wild (Jensen et al., 2015). Such dynamic biosonar adjustments likely contribute to the variation in recorded source parameters reported in many studies.

The source levels of snubfins were comparable to those of sympatric humpback dolphins recorded by de Freitas et al. (2015) and slightly lower than those of Indo-Pacific bottlenose dolphins in the same study (Table I). The centroid frequency of snubfin biosonar was lower than that of both species in said study, while rms bandwidth was higher than that of humpback dolphins but lower than Indo-Pacific bottlenose dolphins. The differences observed in biosonar parameters between these two studies may be due to species-specific differences; however, it is plausible that the different habitats and recording equipment could also contribute to explaining some of the observed differences. For example, a study by Fang et al. (2015) reported lower source levels and shorter bandwidth for Indo-Pacific humpback dolphins in China compared to other dolphin species. The study, however, suffered from recording equipment limitations that likely gave rise to the reported differences. In contrast, source levels and centroid frequency of snubfin echolocation clicks in this study were higher than those reported for the sister species, the Irrawaddy dolphin (Orcaella brevirostris) (Jensen et al., 2013). Given the similar recording equipment and analysis methods, these biosonar differences are likely due to the shallow, cluttered river environment of $O$. brevirostris, where biosonar range may be limited by clutter/reverberation rather than by noise (Jensen et al., 2013). Indeed, other river dolphins inhabiting shallow water environments similarly use higher click rates and lower apparent source levels than marine or coastal delphinids (Ladegaard et al., 2017). The close similarity in on-axis biosonar source parameters between snubfins and sympatric delphinid species raises the question of how future PAM efforts may differentiate similar sized delphinids living in the same area. The high probability of off-axis clicks, and thus different sound parameters, being recorded further hinders efforts and highlights a need for combining click-based detection with whistle-based species discrimination as a possible solution to aid species differentiation.

Overall, the short broadband signal type produced by the Australian snubfin dolphin is appropriate for automated detections using PAM. However, echolocation source parameters recorded in this study varied only slightly from those of closely related species in previous studies. Unknown states of biosonar dynamics, distances and orientation from the recording gear, and different recording arrays may all contribute to variations in reported click values, potentially compounding PAM efforts of sympatric delphinids. Therefore, when establishing source parameter differences for species classification, it is of the utmost importance to record animals with good signal-to-noise ratio, similar behavioural contexts, and distance intervals in order to facilitate accurate discrimination and classification in PAM. Although some may argue that any detection should be seen as a positive result, misclassifying a rare, vulnerable, species in habitats shared with more common sympatric species can falsely inflate population estimates and lead to reduced conservation concerns or misplaced conservation efforts. However, click detections and classifications can potentially be augmented with concurrent whistle classifications to achieve a much lower probability of false alarms. Thus, click detections are required and important to quantify the presence of delphinids, while whistles and other acoustic cues are needed to classify species with very similar vocal outputs whenever possible. Consequently, this study also emphasizes the need for further studies into the probability 
and possibility of discriminating between similarly sized, sympatric coastal delphinids, producing the same types of echolocation clicks.

\section{ACKNOWLEDGMENTS}

We thank the Fitzroy Basin Association for funding fieldwork in Gladstone May 2013 as well as the Australian Marine Mammal Centre who funded J.N.S. with the Bill Dawbin Fellowship and provided fieldwork funding. We also thank Daniele Cagnazzi for fieldwork support in Gladstone in May 2013 and Alex Brown for fieldwork logistics and support in Cygnet Bay, September 2013. We are also deeply thankful to Lars Bejder for facilitating this project and Danuta Wisniewska for helpful comments and discussions on earlier versions of the manuscript. P.T.M. was funded by a Sir Walter Murdoch Honorary Professorship from Murdoch University and frame grants from FNU. F.H.J. was supported by the office of naval research (N00014-1410410) and an AIAS-COFUND fellowship from Aarhus Institute of Advanced Studies, Aarhus University, under EU's FP7 programme (Agreement No. 609033). The research was undertaken under Murdoch University Ethics permit number O2534/12, Departments of Parks and Wildlife permit SF009119 and Great Barrier Reef Marine Park Authority permit G13/35937.1.

Allen, S. J., Cagnazzi, D. D., Hodgson, A. J., Loneragan, N. R., and Bejder, L. (2012). "Tropical inshore dolphins of north-western Australia: Unknown populations in a rapidly changing region," Pacific Conserv. Biol. 18, 56-63.

Au, W. W. L. (1993). The Sonar of Dolphins (Springer, New York).

$\mathrm{Au}$, W. W. L. (2004). "Echolocation signals of wild dolphins," Acoust. Phys. 50, 454-462.

Au, W. W. L., Giorli, G., Chen, J., Copeland, A., Lammers, M., Richlen, M., Jarvis, S., Morrissey, R., Moretti, D., and Klinck, H. (2013). "Nighttime foraging by deep diving echolocating odontocetes off the Hawaiian islands of Kauai and Ni'ihau as determined by passive acoustic monitors," J. Acoust. Soc. Am. 133, 3119-3127.

Beasley, I., Robertson, K. M., and Arnold, P. (2005). "Description of a new dolphin, the Australian snubfin dolphin Orcaella heinsohni SP. N. (cetacea, delphinidae)," Mar. Mammal Sci. 21, 365-400.

Beedholm, K., and Møhl, B. (2006). "Directionality of sperm whale sonar clicks and its relation to piston radiation theory," J. Acoust. Soc. Am. 119, EL14-EL19.

Bejder, L., Hodgson, A. J., Loneragan, N., and Allen, S. J. (2012). "Coastal dolphins in north-western Australia: The need for re-evaluation of species listings and short-comings in the Environmental Impact Assessment process," Pacific Conserv. Biol. 18, 22-25.

Berg Soto, A., Marsh, H., Everingham, Y., Smith, J. N., Parra, G. J., and Noad, M. (2014). "Discriminating between the vocalizations of IndoPacific humpback and Australian snubfin dolphins in Queensland, Australia," J. Acoust. Soc. Am. 136(2), 930-938.

Brown, A. M., Bejder, L., Cagnazzi, D., Parra, G. J., and Simon, J. (2012). "The North West Cape, Western Australia: A potential hotspot for IndoPacific Humpback Dolphins Sousa chinensis?," Pacific Conserv. Biol. 18, 240-246.

Brown, A. M., Kopps, A. M., Allen, S. J., Bejder, L., Littleford-Colquhoun, B., Parra, G. J., Cagnazzi, D., Thiele, D., Palmer, C., and Frère, C. H. (2014). "Population differentiation and hybridisation of Australian snubfin (Orcaella heinsohni) and Indo-Pacific humpback (Sousa chinensis) dolphins in North-Western Australia," PLoS One 9, e101427.

Chatto, R., and Warneke, R. M. (2000). "Records of cetacean strandings in the Northern Territory of Australia," Beagle Rec. Museums Art Gall. North. Territ. 16, 163-175.

de Freitas, M., Jensen, F. H., Tyne, J., Bejder, L., and Madsen, P. T. (2015). "Echolocation parameters of Australian humpback dolphins (Sousa sahulensis) and Indo-Pacific bottlenose dolphins (Tursiops aduncus) in the wild," J. Acoust. Soc. Am. 137, 3033-3041.

Fang, L., Li, S., Wang, K., Wang, Z., Shi, W., and Wang, D. (2015). "Echolocation signals of free-ranging Indo-Pacific humpback dolphins (Sousa chinensis) in Sanniang Bay, China," J. Acoust. Soc. Am. 138, 1346-1352.

Fenton, B. M. B., Jensen, F. H., Kalko, E. K. V., and Tyack, P. L. (2014). "Sonar signals of bats and toothed whales," in Biosonar, edited by A. Surlykke, P. E. Nachtigall, R. R. Fay, and A. N. Popper (Springer, New York), pp. 11-59.

Janik, V. M., and Sayigh, L. S. (2013). "Communication in bottlenose dolphins: 50 years of signature whistle research," J. Comp. Physiol. A Neuroethol. Sens. Neural Behav. Physiol. 199, 479-489.

Jensen, F. H., Rocco, A., Mansur, R. M., Smith, B. D., Janik, V. M., and Madsen, P. T. (2013). "Clicking in shallow rivers: Short-range echolocation of Irrawaddy and Ganges river dolphins in a shallow, acoustically complex habitat," PLoS One 8, e59284.

Jensen, F. H., Wahlberg, M., Beedholm, K., Johnson, M., de Soto, N. A., and Madsen, P. T. (2015). "Single-click beam patterns suggest dynamic changes to the field of view of echolocating Atlantic spotted dolphins (Stenella frontalis) in the wild," J. Exp. Biol. 218, 1314-1324.

Kyhn, L. A., Jensen, F. H., Beedholm, K., Tougaard, J., Hansen, M., and Madsen, P. T. (2010). "Echolocation in sympatric Peale's dolphins (Lagenorhynchus australis) and Commerson's dolphins (Cephalorhynchus commersonii) producing narrow-band high-frequency clicks," J. Exp. Biol. 213, 1940-1949.

Kyhn, L. A., Tougaard, J., Jensen, F. H., Wahlberg, M., Stone, G., Yoshinaga, A., Beedholm, K., and Madsen, P. T. (2009). "Feeding at a high pitch: Source parameters of narrow band, high-frequency clicks from echolocating off-shore hourglass dolphins and coastal Hector's dolphins," J. Acoust. Soc. Am. 125, 1783-1791.

Kyhn, L. A., Tougaard, J., Thomas, L., Duve, L. R., Stenback, J., Amundin, M., Desportes, G., and Teilmann, J. (2012). "From echolocation clicks to animal density-Acoustic sampling of harbor porpoises with static dataloggers," J. Acoust. Soc. Am. 131, 550-560.

Ladegaard, M., Jensen, F. H., Beedholm, K., da Silva, V. M. F., and Madsen, P. T. (2017). "Amazon river dolphins (Inia geoffrensis) modify biosonar output level and directivity during prey interception in the wild," J. Exp. Biol. 220, 2654-2665.

Madsen, P. T., and Wahlberg, M. (2007). "Recording and quantification of ultrasonic echolocation clicks from free-ranging toothed whales," Deep Sea Res. Part I: Oceanogr. Res. Pap. 54, 1421-1444.

Marques, T. A., Thomas, L., Ward, J., DiMarzio, N., and Tyack, P. L. (2009). "Estimating cetacean population density using fixed passive acoustic sensors: An example with Blainville's beaked whales," J. Acoust. Soc. Am. 125, 1982-1994.

Moore, P. W., Dankiewicz, L. A., and Houser, D. S. (2008). "Beamwidth control and angular target detection in an echolocating bottlenose dolphin (Tursiops truncatus)," J. Acoust. Soc. Am. 124, 3324-3332.

Moore, P. W. B., and Patterson, S. A. (1983). "Behavioral control of echolocation source level in the dolphin (Tursiops truncatus)," in Proceedings of the Fifth Biennial Conference on the Biology of Marine Mammals, November 27-December 1, Boston, MA, p. 70.

Moore, P. W. B., and Pawloski, D. A. (1990). "Investigations on the Control of Echolocation Pulses in the Dolphin (Tursiops truncatus)," in Sensory Abilities of Cetaceans, edited by J. A. Thomas and R. A. Kastelein, (Springer, New York), pp. 305-316.

Palmer, C., Murphy, S. A., Thiele, D., Parra, G. J., Robertson, K. M., Beasley, I., and Austin, C. M. (2011). "Analysis of mitochondrial DNA clarifies the taxonomy and distribution of the Australian snubfin dolphin (Orcaella heinsohni) in northern Australian waters," Mar. Freshw. Res. 62, 1303-1307.

Palmer, C., Parra, G. J., Rogers, T., and Woinarski, J. (2014). "Collation and review of sightings and distribution of three coastal dolphin species in waters of the Northern Territory, Australia," Pacific Conserv. Biol. 20, $116-125$.

Parra, G. J., Corkeron, P. J., and Marsh, H. (2006a). "Population sizes, site fidelity and residence patterns of Australian snubfin and Indo-Pacific humpback dolphins: Implications for conservation," Biol. Conserv. 129, $167-180$

Parra, G. J., Schick, R., and Corkeron, P. J. (2006b). "Spatial distribution and environmental correlates of Australian snubfin and Indo-Pacific humpback dolphins," Ecography (Cop.) 29, 396-406.

Reeves, R. R., Jefferson, T. A., Karczmarski, L., Laidre, K., O’Corry-Crowe, G., Rojas-Bracho, L., Secchi, E. R., Slooten, E., Smith, B. D., Wang, J. Y., and 
Zhou, K. (2008). "Orcaella heinsohni," IUCN Red List of Threatened Species, http://www.iucnredlist.org/details/136315/0 (Last viewed November 5, 2015).

Roch, M. A., Klinck, H., Baumann-Pickering, S., Mellinger, D. K., Qui, S., Soldevilla, M. S., and Hildebrand, J. A. (2011). "Classification of echolocation clicks from odontocetes in the Southern California Bight," J. Acoust. Soc. Am. 129, 467-475.

Van Parijs, S. M., Parra, G. J., and Corkeron, P. J. (2000). "Sounds produced by Australian Irrawaddy dolphins, Orcaella brevirostris," J. Acoust. Soc. Am. 108, 1938-1940.
Wahlberg, M., Jensen, F. H., Aguilar Soto, N., Beedholm, K., Bejder, L., Oliveira, C., Rasmussen, M., Simon, M., Villadsgarrd, A., and Madsen, P. T. (2011). "Source parameters of echolocation clicks from wild bottlenose dolphins (Tursiops aduncus and Tursiops truncatus)," J. Acoust. Soc. Am. 130, 2263-2274.

Wisniewska, D. M., Johnson, M., Teilmann, J., Rojano-Doñate, L., Shearer, J., Sveegaard, S., Miller, L. A., Siebert, U., and Madsen, P. T. (2016). "Ultra-high foraging rates of harbor porpoises make them vulnerable to anthropogenic disturbance," Curr. Biol. 26, 1441-1446. 